\title{
Study on WAMAC System Architecture Design, Including PMU Data Verification System
}

\author{
Jun-Hee $\mathrm{Cho}^{+} \cdot \mathrm{Mi}-\mathrm{H} w a \mathrm{Choi}^{++} \cdot$ Myeong-Woo Lee ${ }^{+++} \cdot$ Sang-Tae $\mathrm{Kim}^{++++} \cdot$ Doug-Je Woo ${ }^{+++++}$
}

\begin{abstract}
PMU based power grid monitoring and control system, WAMAC (Wide Area Monitoring And Control) system is required system design for accurate power data without error and loss through a system-wide. In the paper, we propose system design that measured data from PMU transmitted without loss to PDC and DSM server. and we propose a method to verify the real-time "data has been transmitted accurately". Verification system has been designed to reflect the WAMAC system. Therefore the WAMAC can enhance the reliability of the analysis of the data, and it can monitor lossless real-time trend data.
\end{abstract}

Keywords: WAMAC(Wide Area Monitoring And Control), PMU(Phasor Measurement Unit), IEEE C 37.118, Smart Grid

\section{PMU Data 검증시스템을 포함한 $\mathrm{WAMAC}$ 시스템 설계에 관한 연구}

조 준 희 ${ }^{+} \cdot$ 최 미 화 ${ }^{++} \cdot$ 이 명 우 $^{+++} \cdot$ 김 상 태 ${ }^{++++} \cdot$ 우 덕 제 ${ }^{+++++}$

요 약

PMU 기반 전력계통의 감시제어 시스템인 WAMAC(wide area Monitoring and control) 시스템은 PMU에서 계측된 정밀한 전력데이터를 시스템 전반에 손실 및 오류없이 전달/검증하기 위한 시스템의 설계가 요구되었다. 이에 본 논문에서는 PMU에서 발생된 계측 데이터가 PDC, DSM Server 등 시스템 전반을 거쳐서 데이터 손실이 발생하지 않도록 설계 하였으며 각 시스템별로 필요한 샘플링만큼 정확히 전송되고 있는 지를 검증하는 방법에 대해 제안한다. 효과적인 검증을 위해 본 논문에서는 각 시스템의 테스트 시스템을 구성하고 각 시스템들에서 들어오는 샘플링 데이터를 저장하는 방식(규약)을 만들었다. 또한, 해당 $\mathrm{PMU}$ 에서 $\mathrm{PDC} / \mathrm{PDC}$ 에서 $\mathrm{DSM}$ 서버간의 무손실 검증을 위해 본 논문에서 제안 한 샘플링 방식을 검증 프로그램을 설계하고 만들어 $\mathrm{PMU}$ 와 상위시스템 간의 데이터 무손실을 검증할 수 있음을 프로그램 적으로 확인하였다. 이 검증시스템에 WAMAC 시스템에 반영되도록 설계함으로써 WAMAC UI를 통하여 도출되는 분석데이터와 예측 결과의 신뢰성을 한층 높일 수 있게 될 것이다.

키워드 : WAMAC(Wide Area Monitoring And Control), 고정밀페이저측정장치, IEEE C 37.118, 스마트그리드

\section{1. 서 론}

스마트 그리드(SMART Grid)란 지능형 전력망을 뜻하는 용어로써 기존 전력망에 정보기술(IT)을 접목하여, 전력공급 자와 소비자가 양방향으로 실시간 정보를 교환하고 에너지 효율을 최적화하는 차세대 전력망을 말한다. 실시간으로 전 력상황을 모니터링 할 수 있는 시스템이 구축되어야 하는

† 정 회 원: (주)팜즈커뮤니케이션 연구소장

†† 비 회 원: (주)팜즈커뮤니케이션 상무이사

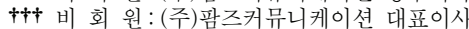

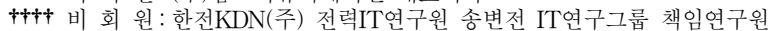

†+十† 비 회 원: 한전 $\mathrm{KDN}$ (주) 전력IT연구원 송변전 IT연구그룹 선임연구원 논문접수 : 2012 년 11월 7일

심사완료 : 2012년 11월 15일

* Corresponding Author: Jun-Hee Cho(netbelle@gmail.com)
것이 스마트그리드의 기초라고 할 수 있다. 이에 WAMAC 시스템은 대한민국 전 지역에 분포되어 있는 발전소/변전소 에 고정밀페이저측정장치(PMU:Phasor Measurement Unit) 를 설치하여 교류전압, 전류의 위상, 주파수의 변화율 등의 고정밀 전력데이터를 초당 60회 측정함과 동시에 위성신호 (GPS)를 이용하여 측정데이터에 백만분의 1 초 단위로 시간 을 표시함으로써 전국 각 지역의 전력데이터를 시각동기화 하여 측정할 수 있다. 이 측정 데이터를 기반으로 전력계통 운영자들에게 실시간으로 계통상황 정보를 제공하여 실시간 온라인 전압, 주파수, 위상의 감시가 가능해 진다. WAMAC 시스템은 변전소에 설치된 $\mathrm{PMU}$ 가 $\mathrm{GPS}$ 를 통하여 시간을 동기화해 측정된 전압, 전류 및 주파수 등을 받아 WAMAC 서버시스템으로 실시간 데이터를 보내 계통 상황을 감시, 
안전성을 평가.예측한다. 기존 시스템들이 매 2 5초 마다 정보를 수집했다면 WAMAC는 1초에 60회의 데이터를 수 집하여 실시간성을 보장한다. PMU에서 측정된 데이터들은 실시간 계통 분석, 계통의 상태추정, 사고의 사후 분석 등 다양한 형태로 사용되기 때문에 WAMAC 시스템 내에서 $\mathrm{PMU}$ 에서 측정된 초당 60 회의 데이터들이 손실없이 계층별 서버에 전달이 되고 각 분석 모듈에서 정확한 데이터들로 알고리즘의 결과가 계산되는지 확인할 수 있는 검증 시스템 이 필요하게 되었다.

본 논문에서는 $\mathrm{PMU}$ 에서 측정된 데이터들이 $\mathrm{PDC}$ 에 손실 없이 전달이 되었는지 $\mathrm{PDC}$ 에서 전송한 데이터들이 $\mathrm{DSM}$ 서버에 손실 없이 전달이 되었는지 확인하는 시스템을 구성 하고 IEEE C37.118-2005 표준[1]을 기반으로 한 vPMU를 통해 측정데이터를 발생시키고, $\mathrm{PDC}$ 를 거쳐 $\mathrm{DSM}$ 까지 전달 되는 테스트 환경을 구축하여 PMU 별 데이터의 전송 현황 을 감시할 수 있는 시스템을 개발하였으며 이를 통하여 향 후에 PMU 추가 증설/폐쇄 시 또는 예측될 수 없는 데이터 가 측정되었을 때에도 손실 없이 데이터가 상위시스템으로 전송되는 것을 검증할 수 있는 시스템을 도입하였다.

정확한 데이터 검증을 포함한 WAMAC 시스템의 도입은 현재 실시간으로 제공되지 못했던 전력 시스템 운영에 필요 한 각종 데이터들을 안정적으로 제공함으로써 전력 시스템 의 안정성 및 신뢰도를 획기적으로 발전시킬 수 있으며 대 정전사고 방지를 위한 초석이 될 수 있다. 또한 스마트그리 드를 기반으로 한 신재생에너지인 풍력, 태양열, 조력 등의 친환경 에너지의 공급시에도 실시간 모니터링 및 제어를 가 능하게 해주는 기초적인 분석 자료를 제공할 수 있게 된다.

\section{2. 관련 연구}

\subsection{PMU(Phasor Measurement Unit)}

대규모의 전력계통 운전상태를 모니터링하기 위하여 계측 장치에는 계통정수측정장치(PQVF), 고장기록장치(FR:Fault Recoder), 전력계통상태감시장치 $4(\mathrm{PSDM})$, 그리고 $\mathrm{PMU}$ 가 있다.

PMU를 이용하여 취득된 데이터는 GPS 수신장치를 통하 여 GPS 시간으로 시각동기화된 페이저 데이터이다. 이는 전 계통으로부터 동기화된 신호를 취득할 수 있고 개통동요현상 등을 실시간으로 감시할 수 있는 기능을 제공할 수 있으며, 그뿐 아니라 최대 초당 60 회까지 데이터를 측정함으로써 전 력계통의 특성과 현상을 실시간으로 분석할 수 있다.

WAMAC System은 PMU로부터 변전소와 발전소에서 측정한 데이터를 기반으로 전국 송전망에 대한 실시간 상황 분석과 주요 지역의 $\mathrm{PMU}$ 데이터를 이용하여 전압과 전력 의 흐름을 실시간으로 정밀하게 파악할 수 있게 되었다.

실시간 PMU 데이터를 기반으로 전력계통 상황분석데이 터를 계산할 수 있는 미소신호안정도, 취약도, 전압안정도 등의 알고리즘을 탑재하여 WAMAC을 통하여 모니터링 할 수 있다. 이를 기반으로 하여 장애 발생 등의 문제 상황을 이벤트로 명명하여 사전에 예측하는 것이 가능해 졌다.

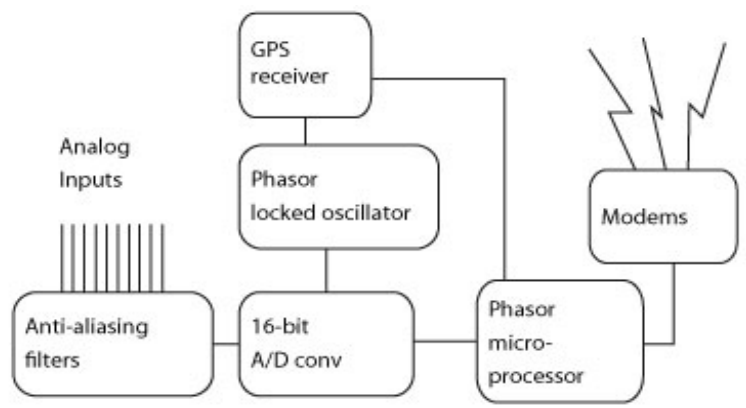

Fig. 1. Block diagram of the Phasor Measurement Unit [3]

IEEE C37.118[1-2]를 통하여 SynchroPhasor 데이터의 실 시간 통신용 메시지 포맷을 기술하고 있다. 메시지 종류는 Data, Configuration, Header, Command 네 종류로 구성된다.

Data message는 PMU에서 만들어진 계측데이터이고, Configuration message는 PMU/DC가 송신하는 데이터와 교정 계수(Calibration factor)에 대한 설명이며 Machinereadable이다. Header message는 사람이 읽을 수 있도록 (Human-readable) 텍스트 형태로 제공되는 $\mathrm{PMU/DC}$ 와 관 련된 설명이며, Command message는 제어 또는 설정을 위 해 $\mathrm{PMU} / \mathrm{DC}$ 로 전송되는 코드이다. Data, Configuration, Header 메시지는 $\mathrm{PMU} / \mathrm{DC}$ 가 상위시스템으로 전송하고 Command는 상위시스템에서 PMU/DC로 전송된다. 여기서 PMU는 Phasor Measurement Unit, (P)DC 는 (Phasor) Data Concentrator를 의미 한다.

$\mathrm{PMU}$ 는 독립적으로 Phasor를 계측, 전송할 수 있고 여러 개의 $\mathrm{PMU}$ 데이터를 $\mathrm{DC}$ 가 수집하여 한꺼번에 전송할 수도 있다.

\begin{tabular}{|c|c|c|c|c|c|c|c|}
\hline & SYNC. & $\begin{array}{l}\text { FRAME } \\
\text { SI ZE }\end{array}$ & DDCODE & SOC & $\begin{array}{c}\text { EBAC, } \\
\text { SEC }\end{array}$ & Dat a Area & CHK \\
\hline size & 2 & 2 & 2 & 4 & 4 & $\pi$ & 2 \\
\hline & \multicolumn{5}{|c|}{ frame header } & frame body & CRC \\
\hline
\end{tabular}

Fig. 2. Message common part

메시지 공통파트의 구성은 Fig. 2와 같다. Data Area를 제외한 나머지 파트는 전체 프레임이 동일하고 frame body 에 해당하는 Data Area는 프레임 종류별로 다른 내용이 채 워진다.

이중 Data Message가 PMU에서 계측된 데이터를 전달하 는 프레임으로 STAT부터 DIGITAL까지 총 6개 파트가 하 나의 block을 구성하며 PMU 개수만큼 block이 반복된다. STAT을 제외한 내용이 가변적인 파트의 구성방식은 configuration frame에 명시된다. 공통부분인 frame header 와 $\mathrm{CHK}$ 를 제외한 frame body구조는 아래와 같다.

\begin{tabular}{|c|c|c|c|c|c|c|c|}
\hline & STAT & PHASORS & FREQ & DFREQ & ANALOG & DIGITAL & Repeat \\
\hline size & 2 & $\begin{array}{c}4 * \text { PHNMB } \\
\text { or } \\
8 * \text { PHNMB }\end{array}$ & $2 / 4$ & $2 / 4$ & $\begin{array}{c}2 * \text { ANNMA } \\
\text { or } \\
4 * \text { ANNMA }\end{array}$ & $2 *$ DGNMA & \\
\hline
\end{tabular}

Fig. 3. Data frame 


\section{WAMAC 시스템 설계}

전국의 발전소 및 변전소에 설치된 PMU로부터 Synchro-Phasor 데이터, Analog, Digital 데이터 수집하여 각 지역제어센터 $(\mathrm{RCC})$ 에 설치되어있는 $\mathrm{PDC}$ (Phasor Data Concentrator)로 전송되고 이 데이터들은 다시 중앙제어센터 (GCC)의 DSM(Distributed Shared Memory)으로 전송된다. $\mathrm{DSM}$ 은 전송받은 데이터를 캐쉬, 분배, 저장하는 시스템이 다. DSM에 전송된 데이터는 DFS(Distributed File System) 를 통하여 파일 기반으로 저장하여 검색, 분석, 장애복구 등 을 수행한다. Algorithm 서버는 Server에서 실시간으로 구 동되는 알고리즘 엔진으로 각 연구기관에서 개발한 분석 알 고리즘에 PMU 데이터, PSS/E 데이터를 입력하고 알고리즘 결과를 저장, 알고리즘 결과에 따른 이벤트의 발생시키고 Event Server가 발생되는 이벤트의 수집 및 분배 처리, 이 벤트 타입별 알람 수준 감시, Notification 이벤트 타입 및 알람 수준 설정 및 관리를 수행한다.

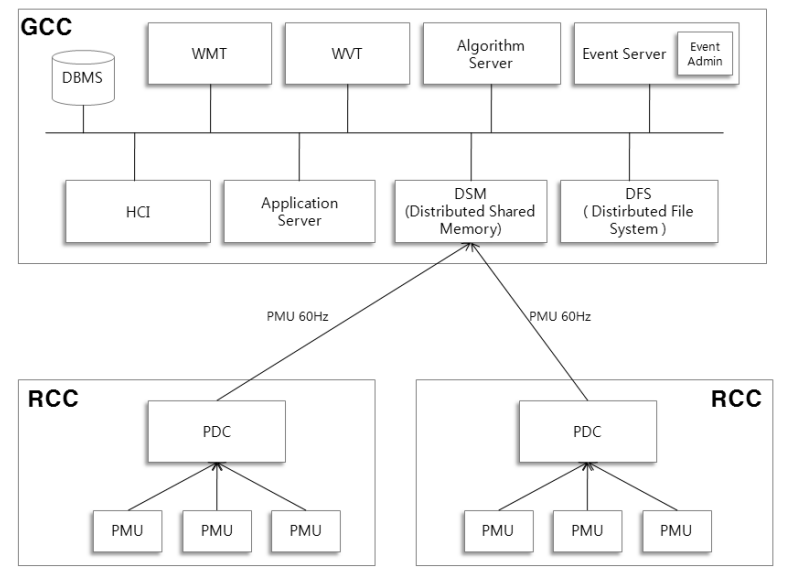

Fig. 4. Architecture of WAMAC System

시스템의 안정성과 $\mathrm{PMU}$ 데이터의 안정적인 제어/관리를 위하여 설계한 Fig 4.의 각 시스템은 다음과 같은 역할을 담당하고 있다.

PDC(Phasor Data Concentrator)는 PMU로 부터 Synchro-Phasor 데이터, Analog, Digital 데이터 수집하여 상위로 전송하는 역할을 하는 장치로써 $\mathrm{RCC}$ 레벨에 1 개 이 상 설치될 수 있다.

$\operatorname{DSM}$ (Digital Shared Memory)은 다수의 RCC레벨에서 수집한 데이터를 상위에서 전송받아 캐쉬, 분배, 저장하는 시스템이다.

DFS(Distributed File System)는 PMU별 $60 \mathrm{~Hz}$ Phasor데 이터를 파일 기반으로 저장 관리하는 시스템으로써 $\mathrm{PMU}$ 데이터의 검색과 분석 처리 장애 복구를 위한 PMU 데이터 의 중복저장 처리를 담당하고 있다.

Event Server는 PMU 데이터 및 알고리즘 결과를 기반으 로 발생되는 이벤트의 수집 및 분배 처리 이벤트 타입별 알 람 수준 감시 및 Notification이벤트 타입 및 알람 수준 설 정 및 관리한다.
Application Server는 HCI의 인증, 검색, 다양한 처리 요 청을 지원하는 미들웨어 시스템이다.

$\mathrm{HCI}$ (Human Computer interface)는 PMU 데이터 실시간 감시, 다양한 알고리즘에 대한 on-line/off-line 감시 분석, 이벤트 감시, 데이터 검색 기능을 제공하는 GUI 화면을 제 공한다.

Algorithm Server는 Server에서 실시간으로 구동되는 알 고리즘 엔진으로 각 연구기관에서 개발한 알고리즘에 PMU 데이터, $\mathrm{PSS} / \mathrm{e}$ 데이터를 입력하고 알고리즘 결과를 저장, 알 고리즘 결과에 따른 이벤트의 발생시키는 역할을 담당한다.

WMT(WAMAC Management Tool)는 WAMAC에서 감 시하고 제어하는 전력 계통의 모델을 관리하고 WAMAC의 운영 시스템들의 정보 및 상태를 관리한다.

WVT(WAMAC Verification Tool)는 WAMAC이 처리해 야하는 대용량 $\mathrm{PMU}$ 데이터 및 이벤트 데이터의 처리 현황 을 감시한다.

\section{1 주요 데이터 처리 흐름 설계}

$\mathrm{PMU}$ 데이터는 $\mathrm{PDC}$ 를 거쳐 $\mathrm{DSM}$ 으로 수집된다. $\mathrm{DSM}$ 는 $\mathrm{PMU}$ 데이터를 필요로 하는 시스템으로 $\mathrm{PMU}$ 데이터를 분 배한다. $60 \mathrm{~Hz}$ 의 원본 데이터와 $10 \mathrm{~Hz}$ 의 샘플링데이터로 데 이터를 분리하여 알고리즘과 시스템에서 요구하는 종류의 데이터를 추출하여 전송한다.

$\mathrm{PDC}$ 의 부팅 프로세스는 Application Server에 자신이 관 리하는 PMU 목록과 PMU별 Configuration 정보를 요청하 여 메모리에 로드한다. PDC UDP Port를 열고 데이터를 수 신한다. 수신된 데이터는 $\mathrm{PMU} \mathrm{ID}$ 를 먼저 확인하고 관리 대 상이 아닌 경우 무시한다. 관리대상 $\mathrm{PMU}$ 인 경우 $\mathrm{PMU}$ 데 이터를 분석하여 DSM으로 전송한다.

$\mathrm{PMU}$ 가 신규 설치될 경우 WAMAC 시스템에 추가로 도 입되기 프로세스는 우선 $\mathrm{WMT}$ 를 통해서 $\mathrm{PMU}$ 정보를 등록 하고 PMU IP, PORT를 이용하여 PMU Configuration정보 와 Header 정보를 요청하여 $\mathrm{DB}$ 에 저장한다. $\mathrm{PMU}$ 신규 등 록 Event를 EventServer에 전송하고 Event Server는 PMU

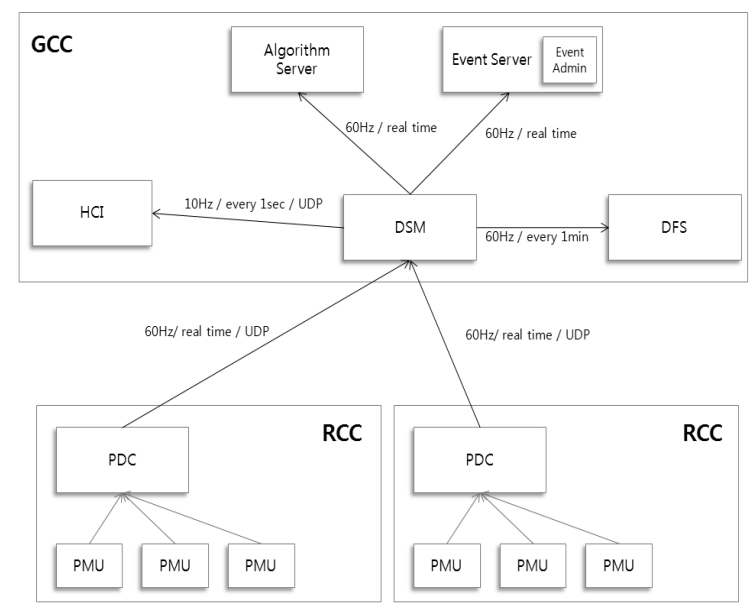

Fig. 5. PMU data transmission Path 


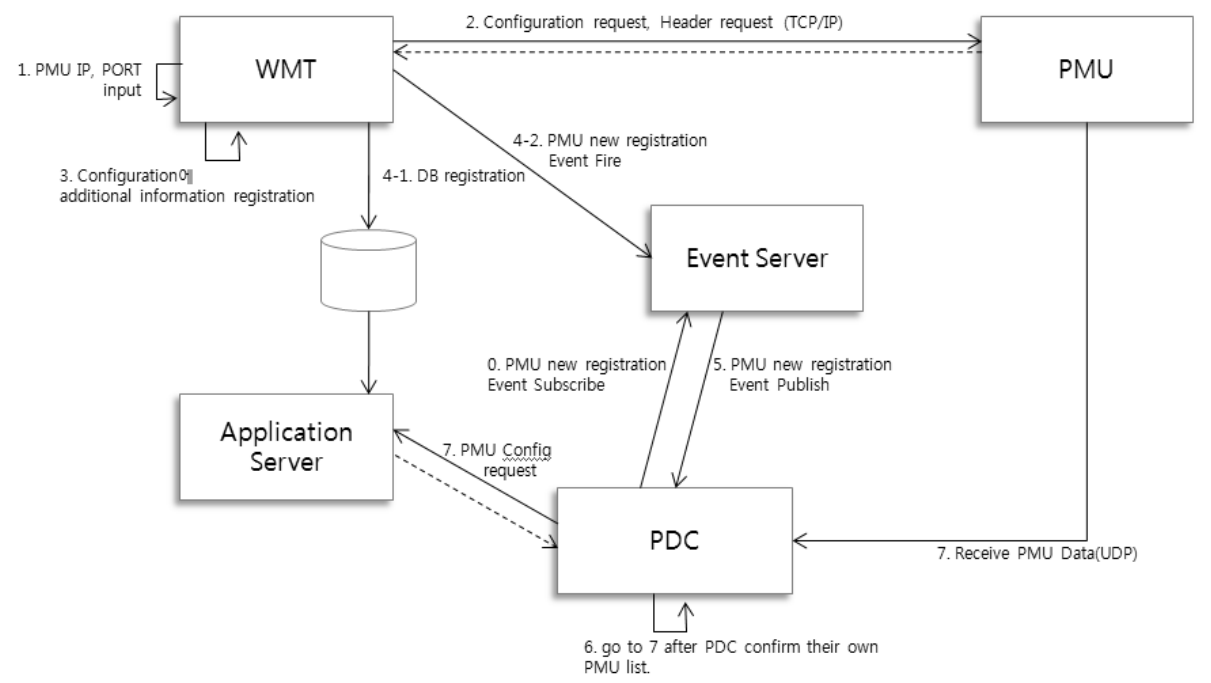

Fig. 6. New PMU registration

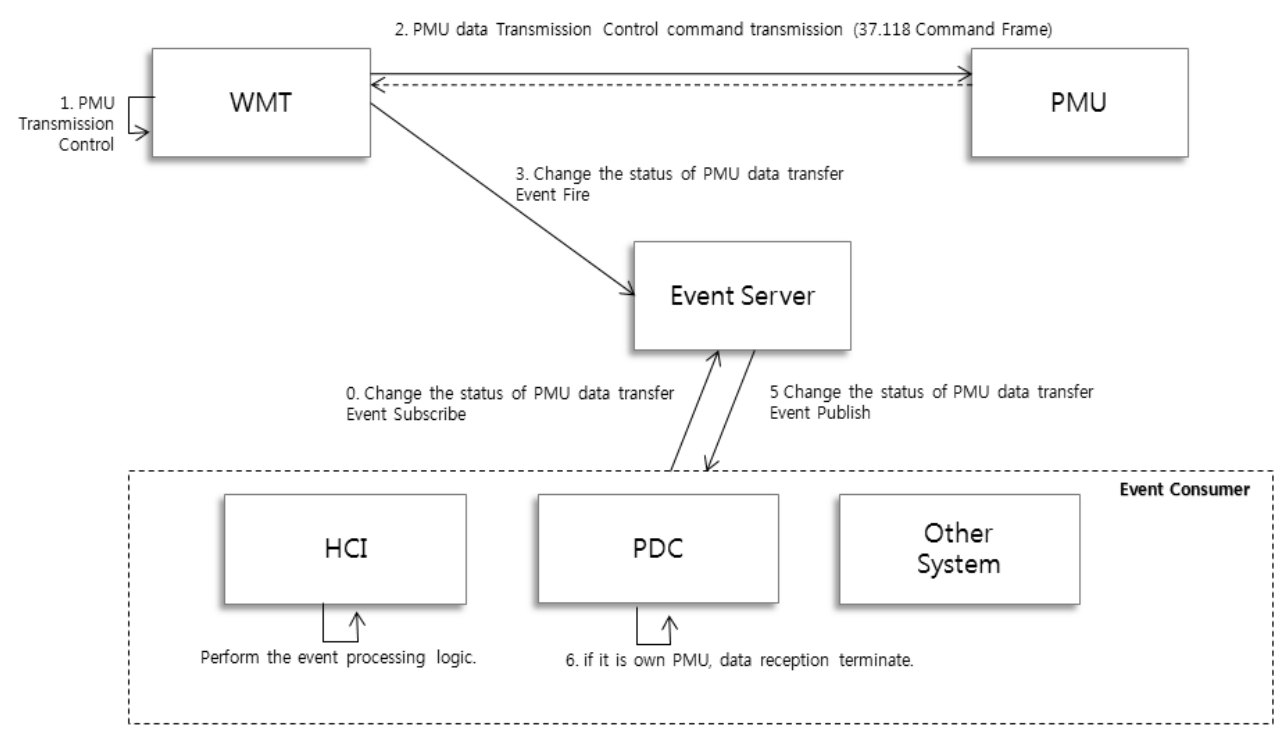

Fig. 7. PMU Data transmission control flow

신규 등록 Event에 가입된 시스템에 이벤트를 전송한다. $\mathrm{PMU}$ 신규 등록 Event를 수신한 $\mathrm{PDC}$ 는 $\mathrm{PMU} \mathrm{ID}$ 로 Application Server에 PMU Configuration 서버 정보를 읽어 와 메모리에 로드한다. $\mathrm{PDC}$ 는 수신된 데이터의 $\mathrm{PMU} \mathrm{ID}$ 를 확인하고 관리대상이 아닌 경우 무시한다. 관리대상 $\mathrm{PMU}$ 인 경우 $\mathrm{PMU}$ 데이터를 분석하여 $\mathrm{DSM}$ 으로 전송한다.

$\mathrm{PMU}$ 데이터는 $\mathrm{PDC}$ 를 거쳐 $\mathrm{DSM}$ 으로 수집된다. $\mathrm{DSM}$ 는 $\mathrm{PMU}$ 데이터를 필요로 하는 시스템으로 $\mathrm{PMU}$ 데이터를 분 배한다. $60 \mathrm{~Hz}$ 의 원본 데이터와 $10 \mathrm{~Hz}$ 의 샘플링 데이터로 데 이터를 분리하여 알고리즘과 시스템에서 요구하는 종류의 데이터를 추출하여 전송한다.

$\mathrm{PDC}$ 의 부팅 프로세스는 Application Server에 자신이 관 리하는 PMU 목록과 PMU별 Configuration 정보를 요청하
여 메모리에 로드한다. PDC UDP Port를 열고 데이터를 수 신한다. 수신된 데이터는 $\mathrm{PMU} \mathrm{ID}$ 를 먼저 확인하고 관리 대 상이 아닌 경우 무시한다. 관리대상 $\mathrm{PMU}$ 인 경우 $\mathrm{PMU}$ 데 이터를 분석하여 DSM으로 전송한다.

$\mathrm{PMU}$ 데이터 전송 제어 흐름은 $\mathrm{WMT}$ 에서 $\mathrm{PMU}$ 데이터 전송 제어 명령을 선택하고 $\mathrm{WMT}$ 는 $\mathrm{PMU}$ 데이터 전송 제 어 명령을 $\mathrm{PMU}$ 에 전송한다. $\mathrm{WMT}$ 는 $\mathrm{PMU}$ 데이터 전송 상태 변경 Event를 Event Server에 보낸다. Event Server는 $\mathrm{PMU}$ 데이터 전송 상태 명령 Event에 가입된 시스템에 이 벤트를 전송한다. $\mathrm{PDC}$ 는 자신이 관리해야하는 $\mathrm{PMU}$ 일 경우 데이터 수신 처리를 종료하는 절차를 수행한다.

$\mathrm{PMU}$ 삭제 처리 흐름은 $\mathrm{WMT}$ 에서 $\mathrm{PMU}$ 삭제를 요청하 면 PMU 삭제 Event를 Event Server에 전송한다. Event 
Server는 PMU 신규 등록 Event에 가입된 시스템에 이벤트 를 전송한다. $\mathrm{PMU}$ 삭제 Event를 수신한 $\mathrm{PDC}$ 는 메모리에 서 $\mathrm{PMU}$ 를 삭제한다.

\section{4. 전송 데이터 검증 시스템 구성}

WAMAC 시스템에서 정확한 실시간 감시 및 분석 결과를 위해서는 $\mathrm{PMU}$ 에서 취득된 측정데이터들이 지역별(RCC) $\mathrm{PDC}$ 와 중앙시스템 $(\mathrm{GCC})$ 의 $\mathrm{DSM}$ 에 손실 없이 전달되어야 한다.

이를 위하여 전송데이터의 검증 시스템이 필요로 하게 되 었다. $\mathrm{PMU}$ 에서 측정된 데이터의 취득시간를 추출하여 초단 위로 취득된 샘플데이터를 계수하고, $\mathrm{PDC}$ 와 $\mathrm{DSM}$ 에서 각각 계산하여 각각의 서버마다 memcached 서버에 저장한다. 이 렇게 저장된 값을 $\mathrm{WVT}$ 에서 읽어서 실제 데이터의 정확도 를 실시간으로 확인할 수 있도록 하였다. 만일 계수된 데이 터의 수가 $\mathrm{PMU}, \mathrm{PDC}, \mathrm{DSM}$ 이 다를 경우 이벤트가 발생하 도록 시스템을 설계하였다. $\mathrm{PMU} \mathrm{ID}$ 를 key값으로 하고 시 간과 샘플데이터의 개수가 저장된 HashMap을 value로 갖 는 HashMap을 생성하였다. 검증시스템에서는 PMU ID별로 처리된 데이터의 시간별 개수를 저장하여 1 초당 처리하는 데이터의 개수를 알 수 있다. 검증시스템에 저장된 데이터 의 개수를 $\mathrm{PMU} \mathrm{ID}$ 와 취득시간, $\mathrm{PMU}, \mathrm{PDC}, \mathrm{DSM}$ 중 어디 에서 전송된 값인지를 확인할수 있는 $\mathrm{Flag}$ 를 두어 이들의 병합한 문자열과 처리한 데이터의 개수를 memcached 서버 에 Map 형태로 저장한다. 이렇게 저장된 데이터를 WVT에 서 매 초마다 memcached 서버를 체크하여 실제 서버들이 처리하고 있는 데이터의 개수를 실시간으로 알 수 있도록 하였다.

WVT에서 memcached Server에 저장된 값을 PMU 별로 보여주어 한 $\mathrm{PMU}$ 가 $\mathrm{vPMU}$ 부터 $\mathrm{PDC}, \mathrm{DSM}$ 까지 정확하게 들어오는지 확인할 수 있도록 사용자 화면을 개발하였다.

데이터베이스에 저장된 $\mathrm{PMU}$ 아이디를 버튼으로 만들어 버튼을 클릭하면 해당 PMU를 선택할 수 있으며 10개까지 선택이 가능하다. 시작버튼을 클릭하면 선택된 PMU마다 memcached 서버에 저장된 데이터 개수를 읽어 화면에 보 여주도록 한다. 시간과 해당 $\mathrm{PMU}$ 의 $\mathrm{PDC}$ 에서의 정확도, $\mathrm{DSM}$ 에서의 정확도를 알 수 있도록 되어 있다. 예를 들어 $\mathrm{PDC}$ 에서 60/60은 $\mathrm{vPMU}$ 에서 60개의 데이터가 $\mathrm{PDC}$ 로 올 라갔으며 $\mathrm{PDC}$ 에서 60 개의 데이터를 처리했다는 의미이다. $\mathrm{DSM}$ (WAMS Server)도 60/60은 PDC에서 60개의 데이터가 $\mathrm{DSM}$ 으로 올라갔으며 $\mathrm{DSM}$ 에서 60개의 데이터를 처리하였 다는 의미이다.

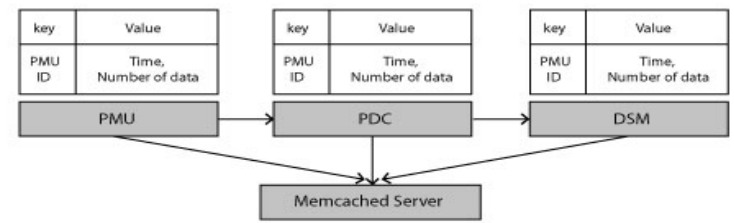

Fig. 8. Architecture of verification system

\section{5. 테스트 환경 구축 및 테스트 결과}

본 논문에서는 테스트를 위하여 WAMAC 시스템 테스트 를 위해 개발된 $\mathrm{vPMU}$ 를 이용하여 테스트 환경을 구축하였 다. 향후 변전소에 PMU가 모두 설치가 되면 실제 PMU 를 기반으로 현 시스템과 테스트를 진행하도록 할 예정이다.

테스트 환경은 하기와 같이 구성하였다.

1. PMU는 vPMU 20대로 구성하였으며 HP probook $5310 \mathrm{~m}$ notebook 컴퓨터에서 동작하였다.

2. $\mathrm{PDC}$ 와 $\mathrm{DSM}$ 은 각각 1 대로 구성하였으며, $\mathrm{HP} \mathrm{rx} 2660(1 \mathrm{P}$ 2core,Memory 8G)에서 동작하였다.

3. memcahced 서버는 1 대로 구성하였으며, HP DL580 v5에 서 동작하였다.

4. vPMU와 PDC는 Hub를 통한 내부네트워크로 구성하였으 며 DSM과 Memcached Server 는 인터넷망을 통하여 연 결하였다. 클라이언트 $\mathrm{PC}$ 의 경우 한 대당 4 개의 $\mathrm{vPMU}$ 를 동작시켜도 $\mathrm{CPU}$ 점유율과 메모리 사용량에 문제가 발생되지 않아서 한 대당 4 개의 $\mathrm{vPMU}$ 를 동작시켰으며 24시간동안 테스트 결과 PDC, DSM memcached Server 모두 $\mathrm{CPU}$ 점유율, 메모리 사용량, 네트워크 트래픽 모두 안정된 상황에서 테스트가 진행되었다.

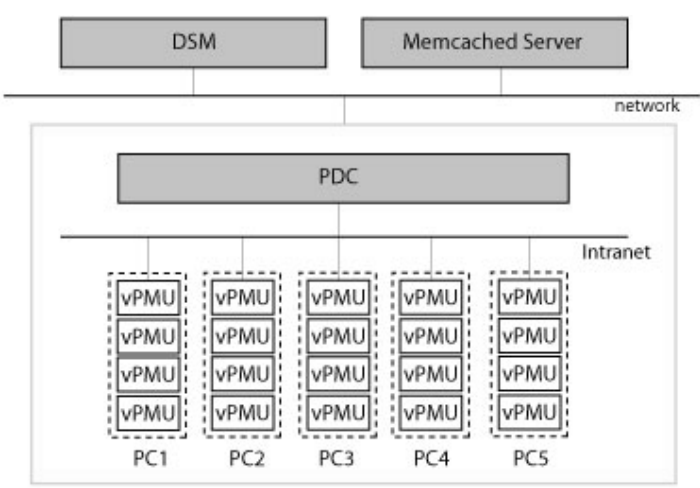

Fig. 9. Architecture of Test bed

아래의 Fig. 10은 $\mathrm{HCI}$ 에 표기된 $\mathrm{PMU}$ 데이터의 검증을 위한 사용자 화면이다.

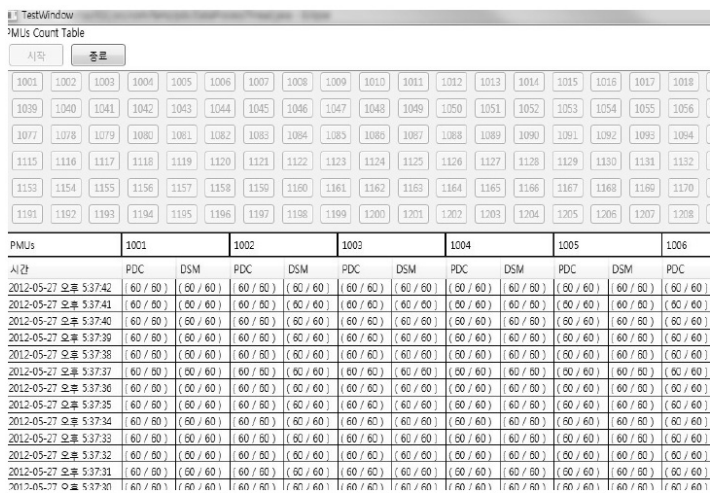

Fig. 10. User interface of verification system 
이 UI 화면을 이용하여 가시적으로 현재 어느 PMU에서 문제가 발생하였는지를 감시 할 수 있으며 이를 통하여 분 석결과의 오류가 잘못된 $\mathrm{PMU}$ 의 측정/전송 결과의 원인으 로 판단할 수 있는 근거를 제시할 수도 있다.

Table 1은 vPMU에서 생성된 데이터와 PDC와 DSM에서 처리한 데이터의 수를 비율적으로 나타낸 것이다. 위 테스 트 환경에서 현재 24시간 동안 테스트 결과 한건의 누락/오 류 데이터 없이 PMU에서 측정된 데이터가 WAMAC 시스 템 전체에서 적용되고 있음을 확인할 수 있다.

Table 1. Experimental results

\begin{tabular}{c|c|c|c|c|c}
\hline & 1 hour & 2 hour & 3 hour & 24 hour & 100 hour \\
\hline PDC & $100 \%$ & $100 \%$ & $100 \%$ & $100 \%$ & $100 \%$ \\
\hline DSM & $100 \%$ & $100 \%$ & $100 \%$ & $100 \%$ & $100 \%$ \\
\hline
\end{tabular}

\section{6. 결 론}

현재 과제를 통하여 1 단계 구축되어진 WAMAC 시스템 을 $\mathrm{vPMU}$ 기반으로 테스트 해본 결과 $100 \%$ 데이터 전송 신뢰도를 보여주고 있다. $\mathrm{vPMU}$ 의 오류로 인하여 초당 61 62 개의 데이터가 생성된 경우에서도 데이터 모두가 정상적 으로 상위 시스템에 전달되고 지고 있다. 현재의 검증시스 템을 통하여 다수의 PMU가 WAMAC 시스템에 추가 도입 되더라도 실시간으로 데이터의 모니터링이 가능하며 만일 문제가 발생될 경우 각각의 $\mathrm{PMU}$ 별로 문제를 분석해 낼 수가 있다.

현재 실제 PMU의 연동이 아닌 $\mathrm{vPMU}$ 로 진행된 테스트 이므로 향후 PMU가 실제 변전소에 설치가 진행되면 실제 $\mathrm{PMU}$ 기반으로 동작을 테스트해 보아야 할 것으로 보인다.

하지만 PMU에서 정확히 데이터가 발생될 경우에는 상위 시스템으로 데이터가 전송되는 것에 대한 검증은 정확히 모 니터링 할 수 있으므로 시스템의 신뢰성을 높이기 위한 목 적으로 본 연구가 진행 되었고, $\mathrm{PMU}$ 설치가 확대 진행될 경우 무손실 데이터 전송에 대한 신뢰성의 평가 도구로 사 용될 것으로 기대한다.

\section{참 고 문 헌}

[1] IEEE Std. C37.118-2005, Synchrophasors for Power Systems

[2] IEEE Std. C37.118.1-2011, IEEE Standard for Synchrophasor Measurements for Power Systems

[3] Bindeshwar Singh, N.K. Sharma, A.N. Tiwari, K.S. Verma and S.N. Singh, "Applications of phasor measurement units (PMUs) in electric power system networks incorporated with FACTS controllers", International Journal of Engineering, Science and Technology Vol.3, No.3, 2011, pp.64-82.

[4] Sang-Tae Kim, Ji-Young Kim, "PerformanceEvaluation for K-WAMS under Field Operating Condition of Korea Power Grid”, 2010 CIGRE

[5] Joe Hughes, The Integrated Energy and Communication Systems Architecture, EPRI Technical Analysis 2004.

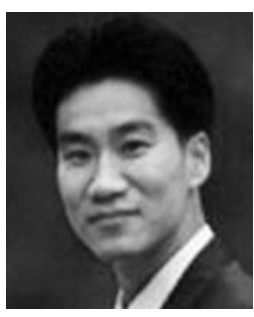

조 준 희

e-mail : netbelle@gmail.com

2002년 서울시립대학교 전산통계학과(학사)

2004년 서울시립대학교 컴퓨터통계학과

(석사)

2010년 서울시립대학교 컴퓨터통계학과 (박사)

현 재 (주)팜즈커뮤니케이션 연구소장

관심분야: Smart Grid, Big Data Analysis, Vision Recognition, Data synchronization, Personal Cloud Computing

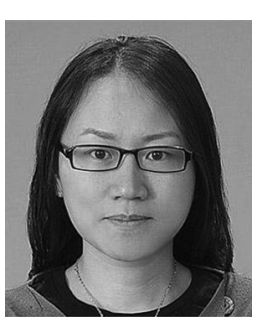

최 미 화

e-mail : magchoi@famz.co.kr

1996년 서울시립대학교 전산통계학과(학사)

2001년 서울시립대학교 컴퓨터통계학과 (석사)

현 재 (주)팜즈커뮤니케이션 상무이사 관심분야: Smart Grid, 대용량/실시간

데이터 처리, IEC 61970 기반의 인터페이스 설계 및 구현

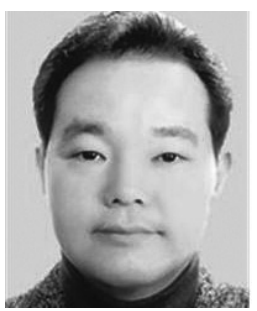

\section{이 명 우}

e-mail :lmw@famz.co.kr

1998년 한성대학교 정보공학과(학사)

2001년 연세대학교 전자계산학과(석사)

현 재 (주)팜즈커뮤니케이션 대표이사 관심분야: Smart Grid

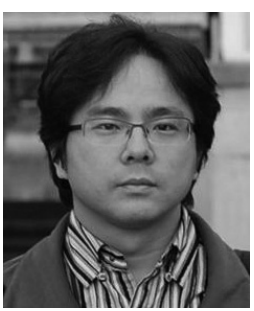

\section{김 상 태}

e-mail : jesteka@kdn.com

1996년 명지대학교 전기공학과(학사) 1998년 명지대학교 전기공학과(석사) 2003년 명지대학교 전기공학과(박사) 현 재 한전 $\mathrm{KDN}$ (주) 전력IT연구원 송변전 IT연구그룹 책임연구원 관심분야:Smart Grid, Synchro-Phasor기반 전력계통 감시제어 기법, 디지털 보호계전기 정정협조기술, 디지털신호 처리기술

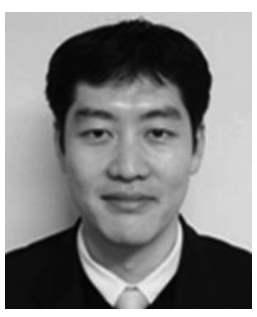

\section{우 덕 제}

e-mail:saintwoo@kdn.com 2003년 한림대학교 정보공학과(학사) 2009년 고려대학교 전산학과(석사) 현 재 한전 $\mathrm{KDN}$ (주) 전력IT연구원 송변전 IT연구그룹 선임연구원 관심분야: 모바일서비스, GIS, 전력시스템 보안, Software Estimation 